\title{
Emerging Appropriate Fuzziness: A Spatiotemporal Observation of Post-Martial Law Taiwan Literature and Cinema
}

\author{
Francis Chia-Hui Lin \\ Faculty of Architecture, Building \& Planning, University of Melbourne, 3010, Victoria, Australia \\ *Corresponding Author: francis.chia.hui.lin@gmail.com
}

Copyright (C) 2014 Horizon Research Publishing All rights reserved.

\begin{abstract}
Taiwan's some four hundred years history, culturally and politically, is inscribed by relationships between rulers and the ruled that shape its social sophistication and gaps between forms of high culture and popular culture. Its built environment, inevitably, echoes this complexity as a representation. Examining Taiwan's very recent built environment, most critically, this phenomenon is highlighted by the uncertainty that translates Taiwan society's anxiety about connecting the yet passed authoritarian past and the seemingly democratic present when its post-war Martial Law period was officially terminated in 1987. This paper observes the immediate historicity today in Taiwan that represents this uncertainty, through scrutinising different cultural forms which the built environment has been identically (re)represented. As a central argument, this paper schematises a context which mediates different spatial objects that are derived from different cultural political origins, literature and cinema, where as texts in one context could be relevant, contradictory or even parallel, and suggests a form of appropriate fuzziness. This form, unlike the social conundrum driven by the awkward cultural and political status of Taiwan society, through ways of urbanisation, geo-identification and spatial idealisation, has pinpointed the possibility that directs Taiwan's spatial evolution on the road ahead.
\end{abstract}

Keywords Urban Sapces, Architecture, Cinema, Literature, Representation, Taiwan

\section{Introduction: High Culture and Popular Culture}

Post-war Taiwan, when read as a text in a quasi-colonial context, has been pinpointed as raising a series of questions in terms of its complexity both in the past and the present: What is post-war Taiwan's de facto scenario particularly after its Martial Law period? Is it related to the collective ideological issue of nationalism? Alternatively, is it related to another circumstance, a comparatively pragmatic concern, the issue of everyday life? Or, simultaneously, are both relevant? These questions are tied into Taiwan's colonial past and its quasi-colonial presence. In this sense, the weight between collectivity and individuality in modern Taiwan society is debatable. Politically, nationalism and the issue of everyday life compete with each other. Culturally, the so-called Chinese orthodoxy as a longstanding high culture in Taiwan is challenged by the emerging indigenous popular culture.

Since the lifting of the Nationalist Government's Martial Law in 1987, which is widely regarded as the commencement of Taiwan's democratisation, the issue of ideological nationalism is no longer dominant. Rather, a pragmatic consciousness about this island's de facto scenario, which emerged as a distinct phenomenon and a historical turning point, is evident in modern Taiwan's chief cultural forms such as literature and cinema. And from then on, Taiwan began to be treated and recognised as an individual subject rather than as a subordinate and subsidiary object.

However, the built environment at Taiwan's post-Martial Law stage, its architecture, concurrently seems to show forms of ambiguity along with this cultural political transition. A straight object-oriented analysis is no longer enough to identify the pivotal texts in Taiwan's spatiotemporal and quasi-colonial context. This paper, therefore, intends to examine spatial reflection from the Martial Law period to the current time by analysing the representations of post-war Taiwan's spatial identification. This identification through space is largely reflected by the domestic political, economic and technological changes in Taiwan after 1987. In this analytical context, different "images" of the typical city and society at different post-war stages in Taiwan have been shown as a critical medium of experience in the discourse of post-war Taiwan's leading cultural forms. In the paper, it argues that there is a form of "appropriate fuzziness" which mediates the state of blurred and sophisticated position in the Taiwanese built 
environment struggling between its autocratic past and the seemingly democratic present.

\section{An Unsettled History: Taiwan and Its Current Inhabitants}

It has been around four hundred years since Taiwan's civilisation has been recorded. During this period, there have been constant shifts between the rulers and the ruled. This is the island's distinguishing characteristic in history, which has dazed and unsettled the island's residents no matter whether in the past or in the present. This situation can be traced to the island's geographic position. Surrounded by oceans and close to nearly all the countries in East Asia, Taiwan has always been an important way station for trans-Pacific voyagers through its geographic location.

Ethnically, there are four groups are recognised in Taiwan worldwide. In the mid-seventeenth century, there were only a small number of migrants in Taiwan. The Austronesian aborigines (often, also called the Formosan aborigines) who had dwelt on Taiwan for some thousands of years were the major inhabitants. When Cheng Cheng-kung brought the first massive Han migrants to Taiwan (1661), it is the root of the major ethnic community today in Taiwan - the native Taiwanese. Apart from the native Taiwanese, the group of the Hakka also formed in Taiwan around this period.

In 1949, Chiang Kai-shek fled to Taiwan after the defeat in the Chinese Civil War against the Communist Party. During this period from 1948 to 1956, he brought enormous numbers of Chinese soldiers and civilians to Taiwan. This import population in Taiwan is now identified as the "mainlanders" as the last ethnic group apart from those islanders who settled in Taiwan before the war (the Formosan aborigines, the native Taiwanese and the Hakka).

\section{Towards Heteroglossia: Subjectivation in Native Writings}

Post-war Taiwan society, on the one hand, has a colourful character derived from both its varied colonial past and recent global impacts. On the other hand, this island has also constructed a series of unique identities in different time periods. In a similar sense, spatial objects which represent and inscribe the traces of history and culture should echo correspondently these historical distinctions as the analytical essential. However, this deduction becomes problematic when it is examined during the recent three decades since 1987. The construction of identity in Taiwan today, and which includes its registration in physical space, is no longer simplified and obvious.

Spatial identification in post-war native Taiwan literature has borne witness to this phenomenon. The Taiwanese writer Wu Cho-Liu's work Orphan of Asia (1959) - originally finished in 1945 in Japanese - describes the orphanhood of Taiwanese people before and after 1945 wherever they lived on the island, the travels to the Chinese "mainland" or the settlements on the Japanese "motherland". The use of a mother tongue was barely recognised at the time; the social position of the islanders of Taiwan both before and after 1945 was always inferior when compared to the colonisers. However this notion was challenged by Chung Li He in his My Native Land (1983) presents a strong nostalgic emotion from the Hakka ethnic group to affiliate with their original country to the Chinese mainland.

From another standpoint, Hsiao Li-hung's Dreams by the White Lake (1996) have reinterpreted the emasculation of the native islanders in Taiwan during the war, as they faced encounters with the Chinese, the Japanese, and the American forces. The sense of cultural belonging at that time was limited to a merely imaginary nationalist illusion, which is the place they have never been to since their birth to the present (Japan, China and even the US). On the other hand, Chu Tien Hsin's The Old Capital: a novel of Taipei (2007) - originally published in 1997 in Chinese - attempts to yearn for the social "evenness" for the Mainlanders when the Taiwanese started to construct the native subjectivity. And this phenomenon is claimed by Chu that it has subordinated the community of the Mainlanders, the "once privileged" ethnic group. This has been strongly stated in her book's very first sentence: "Is it possible that none of your memories count" [1]?

These reflections within popular culture in the post-war native literature, socially and spatially, illustrate a different transition from the Japanese era to the post-war time when compared to the high culture that was constructed under a strong and simplified Chinese nationalism as the official discourse. In this sense, Taiwan's inscriptions of colonisation and the ambivalence to them are able to be pinpointed. In this relationship, different subjects in Taiwan's history are differentiated and positioned. The Japanese Empire, as a coloniser, established Taiwan's modernisation as a modern coloniser due to its westernisation achieved through the Meiji Restoration. And the Nationalist Government after WWII as the replacement government ruled the Taiwan that had turned modern already, presenting a relatively degenerate civilisation due to the longstanding battle in China and the unstable social status of the time. Interestingly, no matter whether Taiwan was colonised by Japanese or Chinese forces, the native inhabitants (which in actual fact should be positioned as the subjects of the island) were both orphanised in colonisation. They were neither Japanese nor Chinese.

Since the rise of Taiwan literature, the manifold unofficial discourses on this island's post-Martial Law cultural political identities thus denote an atmosphere of simultaneous "heteroglossia". In other words, the construction of cultural identity in today's Taiwan is no longer simplified and merely nationalist-based. Rather, the identity is constructed in a hybrid and day-to-day basis, which in fact decentralises the collective state ideology into 
varied social issues of everyday life. Post-Martial Law Taiwan, interestingly, is heading to an awkward stage described by Jameson that "this small island is a non-national nation state" [2]. This small island at this moment is neither a text of Greater China nor the "Taiwan nation" but a multi-accentual, boundary effaced and self-reliant cultural domain running as a de facto independent country.

Pierre Bourdieu has suggested a notion that "the proper name is the support of social identity ... (the proper name) is the true object of all successive rites of institution or nomination, through which the social identity is constructed" [3]. In this sense, multi-accentual heteroglossia in post-Martial Law society has gradually emerged to form post-war Taiwan's quasi-colonial context as well as its proper name. This name is neither political Chinese nationalist nor political Taiwanese nationalist but somewhere in between and it is associated with everyday life of modern Taiwan society, i.e. in architectural and urban aspect - living spaces.

To what extent is post-Martial Law Taiwan legitimised to be connected to the concept of heteroglossia? How does this multi-accentual context compare to the relatively simplified voice in Martial Law society? Multi-accentual context has no intention to define post-Martial Law Taiwan as simple as a departure from a dictatorship but to indicate a more complicated interaction between the Taiwanese and the nation, and native society. Namely, these phenomenological descriptions of being juxtaposed, simultaneous and dispersed in actual fact highlight the distinction between Martial Law Taiwan and its presence in post-Martial Law period. These elements have collapsed the ideological collectivity constructed by the Nationalist Party in the early post-war years, they pragmatically face the reality that today's Taiwan society is not presented as a homogeneous and unique space but on the contrary as a space that accretes different voices that are side-by-side, at the same time and exist individually. Post-Martial Law Taiwan seems to have mirrored the Chinese nationalists' utopian political propaganda (albeit the government of Republic of China is in Taiwan now, it still rules the 35 provinces of China; Taiwan contains no other cultures but orthodox Chinese culture) by pinpointing the realistic fact (Taiwan contains multiple cultures, which are in a precise and determined connection to the island itself). These cultures coexist in the real places of Taiwan, which are able to present Taiwan's diverse historicity and penetrability in history and which have reflected the existence of identified coloniality.

\section{Re-representation of the Post-Martial Law Space: Taiwan Cinema and Beyond}

The context of Taiwan cinema was framed by the growth of native literature, particularly along with the changes after the lifting of Martial Law. The native literature, to a certain degree, became the base of the cinematic works and provided an alternative reflection of public reception in history. Most importantly, the tendency highlighted in the development of post-war literature in Taiwan has given access to the past through popular memory which is different to the top-down official discourse.

At the spatial and practical level, the context of post-Martial Law heteroglossia is shaped by the cultural representation of popular memory. Raymond Williams has indicated the cinema, which works in imitation of the human eye, as an extensively distributed and powerful form of culture [4]. Film, similarly, in post-Martial Law Taiwan's cultural construction, also plays an important role particularly in representing the longstanding suppression of popular memory.

Taiwan cinema was introduced by the Japanese in 1907 and became a popular public medium after 1924 [5]. In the post-war period, Taiwan cinema encountered changes in production procedure from an authoritative to agency-oriented dominance. In the late 1940s, cinema was used as an instrument of the Nationalist Government's authority to eradicate Japanese remnants and to bolster an anti-Communist Polity atmosphere in Taiwan society. Cinema then therefore became a tool of political propaganda; historical and cultural entities were at times twisted for ideological purpose. In the 1950s, Taiwanese Opera became the most popular form of Taiwan cinema. It evoked extensive responses from the public because the use of Taiwan's native language. Regrettably, it went out of date very soon in the 1960s on account of the repressed environment. During that time, native culture and utilising Taiwanese in the use of the language were largely restricted. Instead, the cinematic genre, so-called "health realism", which intended to merely highlight the social ethic and traditions rather than to criticise society, replaced the Taiwanese Opera. This genre later was once again replaced by commercial movies imported from Hong Kong until the 1980s.

Notably, a series of socio-political events shared the importance of the realism and commercialism in the 1970s and the 1980s in Taiwan cinema. In 1971, the position of the ROC in the United Nation was swapped by the PRC. In 1975, Chiang Kai-shek passed away. From 1977 to 1978, heated debate occurred in the field of literature about cultural authenticity. And in 1978, the United States severed diplomatic relations with Taiwan and in 1979, the Kaohsiung Incident happened. These events in the end caused societal anxiety and endangered the Chiang family's dictatorship at that time. Cinema, as the most well-known state apparatus then, was the best path to reflect this phenomenon. Martial Law was lifted in 1987. The ban on the newspaper and the legitimising of the existence of the opposition political party were consequently released before and after this year. The so-called Bentu literature ("native soil", indigenous literature) became the mainstream around this time in Taiwan, which announced the commencement of post-war Taiwan's heteroglossic age. Taiwan cinema, 
inevitably, has followed this tendency creating a new value to reinterpret Bentu materials. Taiwan cinema that used to speak for the nation could now speak for the individual and the community history, the cinematic temperament of authority had already been shifted to a form of agency, this is the so-called "Taiwan New Cinema" period. Since then, "Taiwan" has started to be filled in as a subject in native historiography and individual autonomy has started to challenge the existing nationalist collectivity. Popular memory and the "organised forgotten history", which were habitually taboos in the Martial Law period, therefore have risen to the surface as an experience of Taiwan's social and spatial historiography.

The issue of living spaces, for that reason, has reflected this unwavering temperament from the early post-war stage to the present. Three spatial characteristics, which are always the issues on the island at its post-war stage, have been presented in post-Martial Law Taiwan cinema, and then transferred into concrete spatial form with the cultural political transition of the time: (1) the polemic between the city and countryside, (2) geographic identification, and (3) the idealised space of nostalgia.

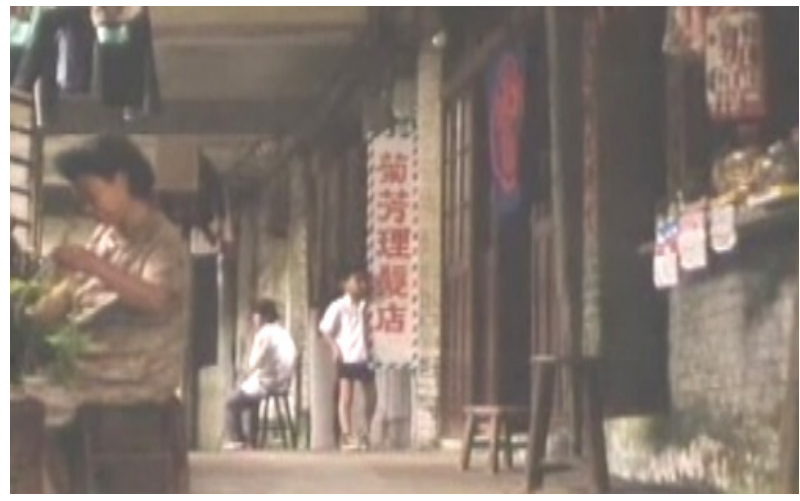

Figure 1. The "city" image in early post-war Taiwan (Duo Sang: $A$ Borrowed Life, directed by Wu Nien-Jen, Taiwan, 1994. Chang Shu A \& V Production, Long Shong Pictures).

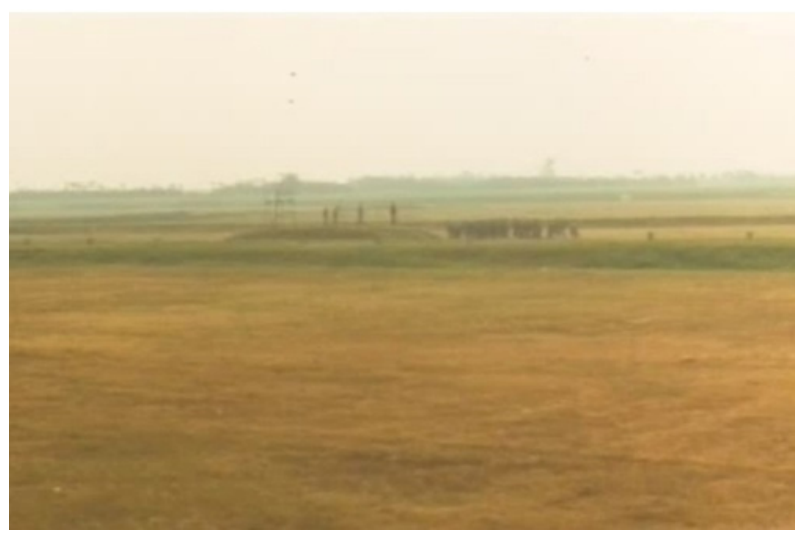

Figure 2. The suburb of Taipei in the early post-war years; it was planned as a military foothold of the time. This image shows not only the metropolitan identity in the Martial Law period but also highlights the political and administrative slant to Taipei City of the time (A Brighter Summer Day, directed by Edward Yang, Taiwan, 1991. ICA, Jane Balfour Films, Yang \& His Gang Filmmakers).

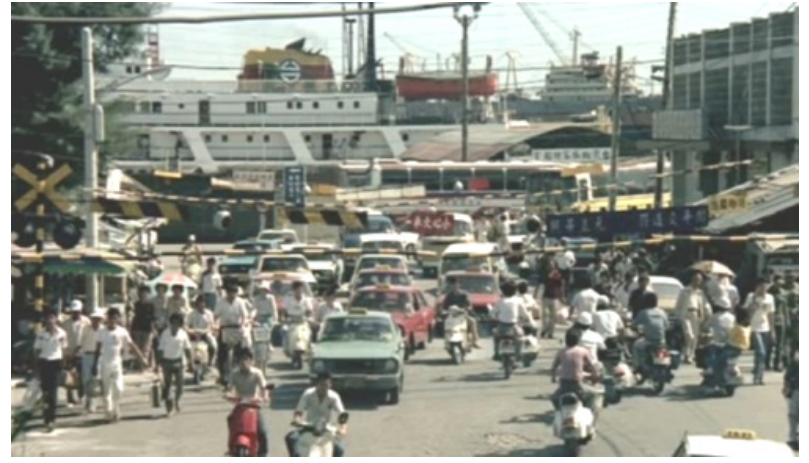

Figure 3. The city image of Kaohsiung in the 1980s. In comparison to Taipei's nationalist and Americanised image, the figure of Kaohsiung represented a strong day-to-day reality and authentic culture of maritime Taiwan apart from the same flourishing image as a major city on the island (The Boys from Fengkoei, directed by Hou Hsiao-hsien, Taiwan, 1983. Wan Nien Ching Ying Yeh).

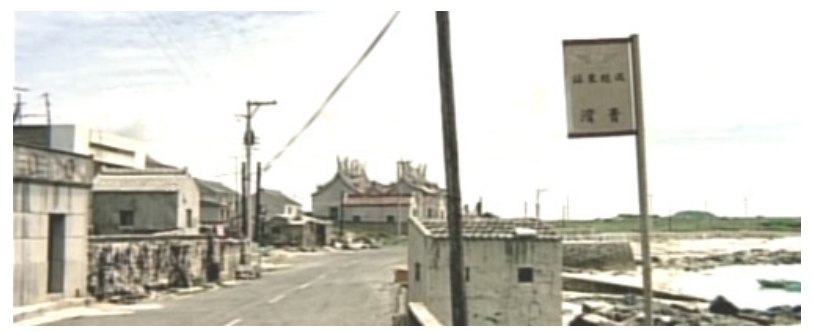

Figure 4. The maritime image of Taiwan (The Boys from Fengkoei, 1983).
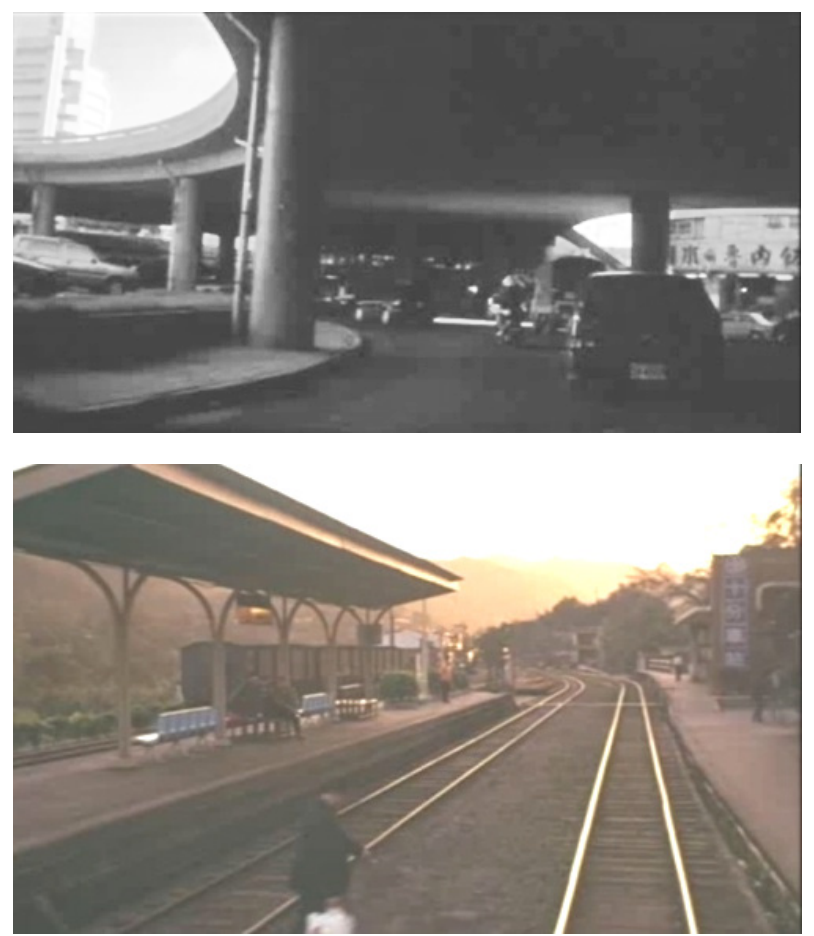

Figure 5. The freeway and railway images filmed to represent the marked spatial characteristics and bridge between the city and the countryside in the 1990s Taiwan (Goodbye South Goodbye, directed by Hou Hsiao-hsien, Taiwan, 1996. 3H Films, Shochiku Corporation).

The polemic between the city and the countryside is an issue in great demand amongst developing countries 
particularly in the Asian region. However, from the early post-war period to the present, taking Taiwan cinema as the example, this issue has been represented by different spatiotemporal concerns experienced within different social contexts of post-war Taiwan. Duo Sang: A Borrowed Life (1994) (Figure 1) reinterprets the very early post-war difference between the city and the countryside, which was distinguished by two issues - livelihood and transportation. A Brighter Summer Day (1991) reconstructs the idea of Taiwan's once "only" metropolis - Taipei City, from the 1950 s to the 1960 s, and the distinctive urban temperament which highlighted the metropolitan identity of American popular cultural and the military footholds (Figure 2). Even so, this ideology has been challenged by works of Taiwan New cinema. The Boys from Fengkoei (1983) records the rise and flourishing of Kaohsiung City (Figure 3 ) instead of the capital city, Taipei. On the other hand, The Boys from Fengkoei starts to observe the characteristics of the countryside from Taiwan's maritime cultural landscape (Figure 4) such as the village image in Penghu instead of the imagination of mainland grassland seen in earlier films. From another observational view, Dust of Angels (1992) and Goodbye South Goodbye (1996) stand for Taiwan's rapid urbanisation between the 1970s and the 1990s, and as evidence, the freeway and the railway have been painted in the film to reduce the difference and distance between the metropolis and the countryside (Figure 5).

Later, Grandma and her Ghosts (1998) shows the social scenario in Taiwan in the late 1990s. The city-countryside polemic highlights the gap between the modern environment and cultural traditions produced by rapid urbanisation. In the movie (and in reality), native cultural traditions such as Chungyuan $P u T u$ are barely seen in metropolitan areas, which have become fundamentally international and placeless. On the other hand, cultural traditions, to a certain degree, have gradually lost their authenticity or been mutated while the modern technologies have become pervasive. For example, the traditional Tao village in Orchid Island represented in Fishing Luck (2005) shows a mutation of indigenous Tao life by importing automobiles, tourism, technologies from Taiwan and on the other hand exporting work force to Taiwan. The traditional tribal landscape in Orchid Island nowadays has become hybrid (Figure 6); it is especially evident from the mutated Tao tribal buildings which combine reinforced concrete structure with traditional stilt house styles (Figure 7). In recent years, problems in environment and community come to the forefront. In Island Etude (2007), the director pinpoints recent popular concerns about indigenous consciousness in Taiwan society. The highly contaminative industries which were usually set in rural areas in the past now need to face debate and strict examination by not only administrative institutes but also NGOs (non-governmental-organisations) which are mostly constituted by community members and academics. The difference and distance between the cities and the rural areas have become comparatively blurred at this stage.
Further, in Cape no.7 (2008) and Su Mi Ma Sen Love (2009), community issues of recovering regional identity in cultural industries, space conservation, building preservation, BOT (Build-Operate-Transfer) and the crisis of losing regional character reinterpret the city-countryside interaction while the city-rural counterbalance simultaneously internationalises and urbanises those "rural" regions (Figure 8).
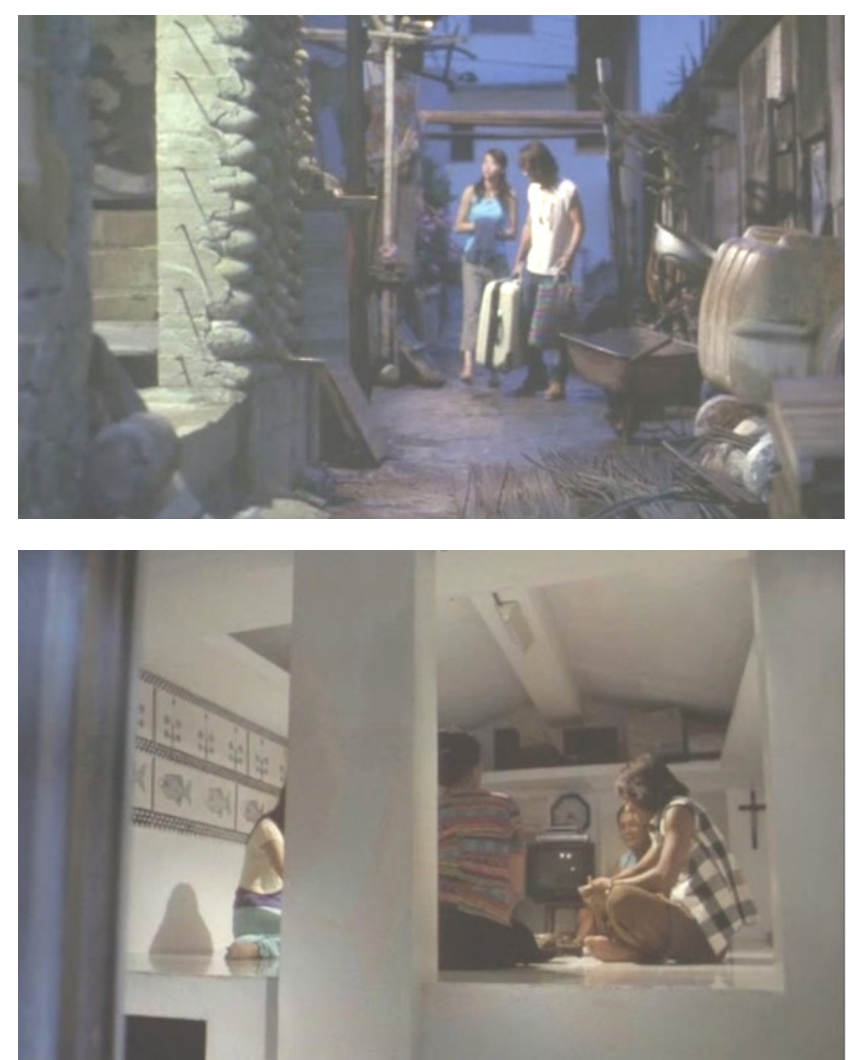

Figure 6. A clear contrast between the modern construction and traditional style in Taiwan's post-war aboriginal tribe which represents the spatial characteristic of hybridisation (Fishing Luck, directed by Tseng Wen-Chen, Taiwan, 2005. Lumiere Motion Picture Corporation).

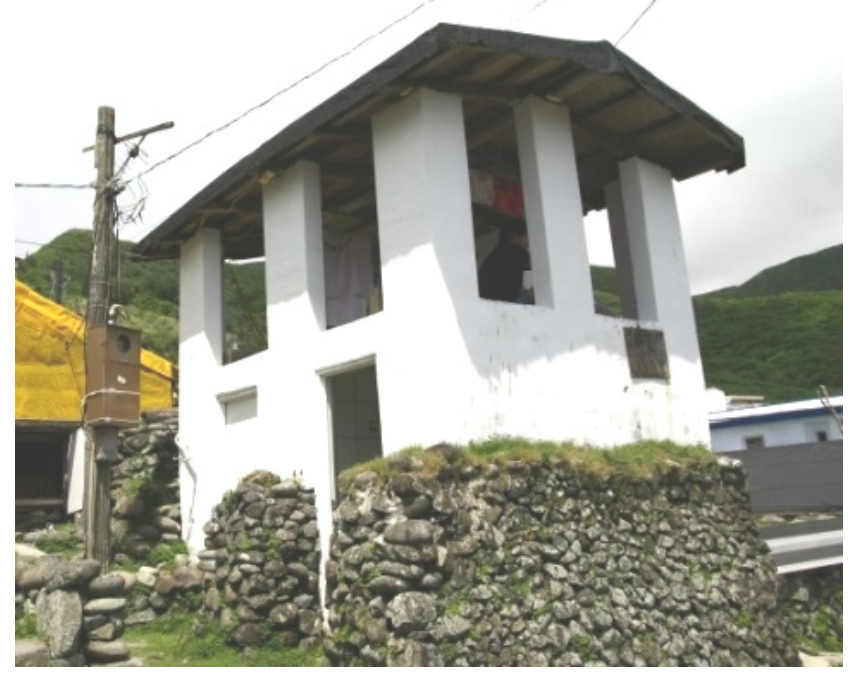

Figure 7. A traditional stilt house constructed with the modern technology in Orchid Island (Taken by the author). 

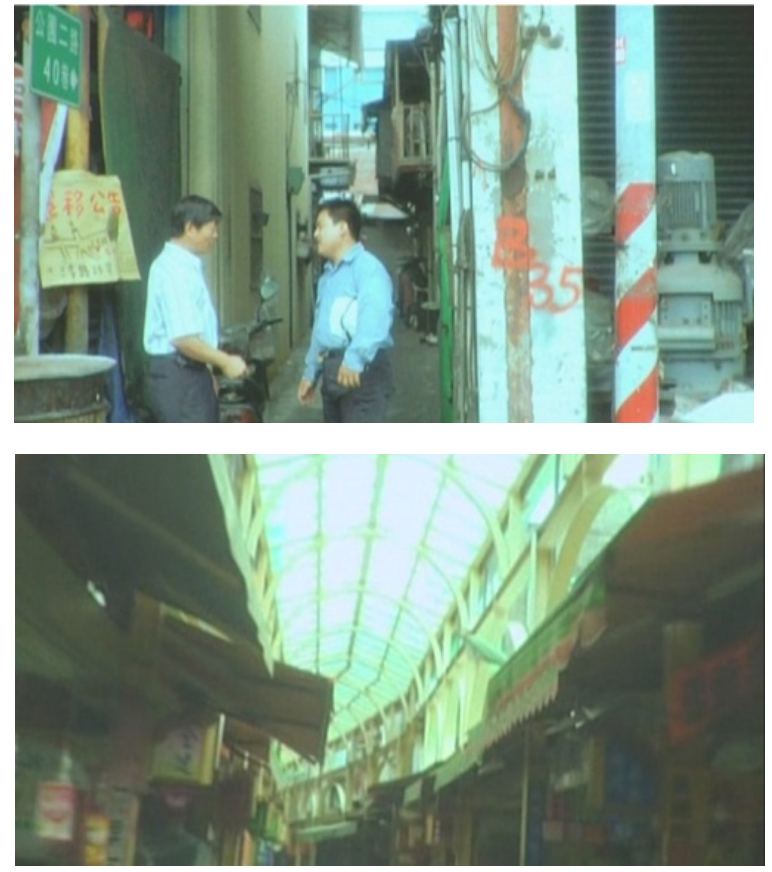

Figure 8. Two images filmed in Su Mi Ma Sen Love show the conflicts happened in community when the renovation of Kaohsiung waterfront was just started (up) and its distinctive result after the renovation (down). The city-countryside interaction at the current stage in Taiwan is addressed by the spatial renovation and revitalisation of regional culture and industries (Su Mi Ma Sen Love, directed by Lin Yu-Hsien, Taiwan, 2009. Joint Entertainment International Inc).

Geographic identification is another moment in space showing a transition of identity construction from the imaginary mainland to the global context. This transition is also linked to the identification process of post-war Taiwan. Taiwan, in its post-war period, was placed as a marginal cultural subdivision of China from the early post-war years to a transitional isolation, and is currently situated as a particular cultural subject (Figure 9). Blue Brave: the Legend of Formosa in 1895 (2008) shows the disappointment felt by Taiwanese people who were abandoned by the Manchu Ching Empire signing the treaty to permanently cede the island and their bitter-sweet Han kin which geographically affiliates with the mainland. But the mainland cast this island away eventually. In stark contrast, Duo Sang: A Borrowed Life presents a strong identification from the group of native Taiwanese after 50 years of Japanisation or even Japan's further impacts on cultural colonisation after 1945. A Japanophilic complex therefore became the most difficult obstacle for the KMT government who wanted to remove it from the island but without success. This sense of frustration, felt by the Mainlanders, is evident when observed in A Brighter Summer Day. The film marks the awkward sense of the Mainlanders who look at Taiwan as a temporary settlement or new territory. This group of newcomers represents the privilege granted to take over all the properties the Japanese had left behind. But it also depicts their resignation to have to live and work in those fundamentally Japanese style buildings. During this period, the geographic sense of belonging and the cultural identity were strongly imaginary and nationalist, and constructed following the ideology of the Chinese mainland and Greater China that was in fact not relevant to the island's real life but a compelling imposition.

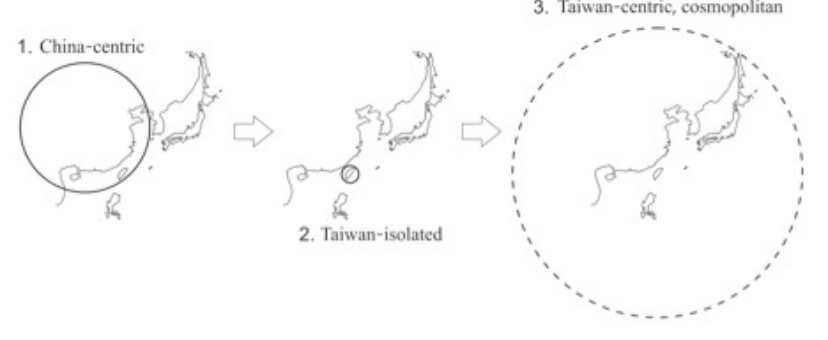

Figure 9. The transition of geographic identification in post-war Taiwan, the numbers show three chronologic stages of the geographic sense of belonging constructed by scales and centres in the imaginary mainland, the isolated island and the present global context (Made by the author).

The sense of indigenisation raised in the period between the 1970s and the 1990s made the identification move towards another form of nationalist thinking - Taiwan nationalism. Hou's works, such as The Boys from Fengkoei, A City of Sadness, Dust of Angels, and Goodbye South Goodbye, all demonstrate this transition of environmental identification. The scenes these films have shown are restricted to the island's regions only and the characterised locations in the films are only markets and street landscape (Figure 10). That is to say, it seems that all the external impacts had been carefully filtered and rejected, except the island's insularity.
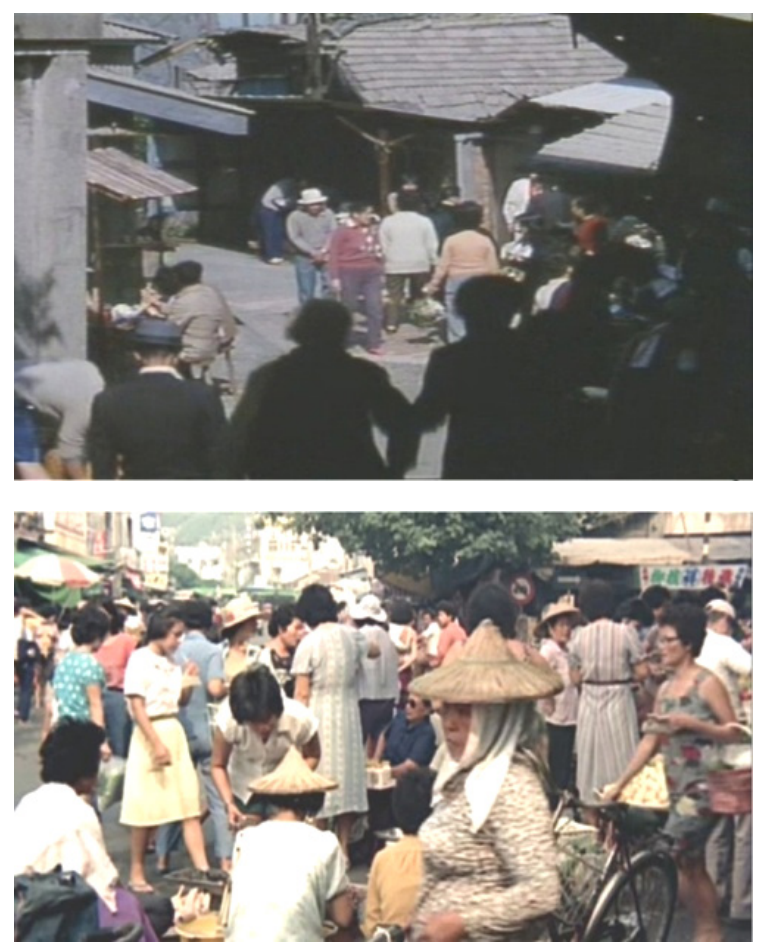

Figure 10. The market images largely appear in the films as the public and identified scenes of Taiwan in the 1970s (Up: A City of Sadness, directed by Hou Hsiao-hsien, Taiwan, 1989. British Film Institute. Down: The Boys from Fengkoei, 1983). 
After the Martial Law period, this situation was once again altered and extended to a cosmopolitan scale when geo-identification was centralised in Taiwan with an indigenous consciousness and a form of consensus which emerged in the 1990s. More precisely, after the late 1990s, the senses of globalisation and indigenisation have become the chief texts within the context of Taiwan's geographic identification (Figure 11). The isolated and placeless urbanisation seems no longer enough to support any focus on the identification of place. As a reflection, the existing spatial traces of native history such as the old gate highlighted in Cape No.7 become noticeable landmarks. Without a doubt, the so-called "native site" in this sense has already become "Taiwan" rather than those imaginary and untouchable images, such as Mongolian grassland, once upon a time.
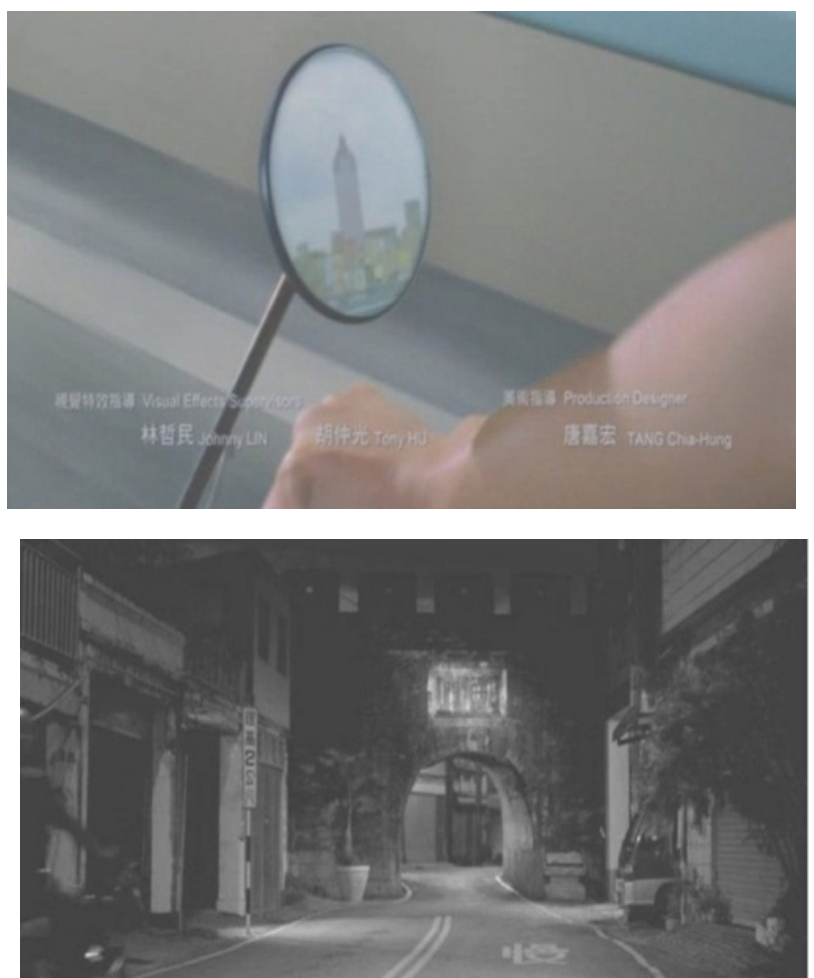

Figure 11. Two images, in Cape No.7, filmed the moment when the protagonist was riding a motorbike out of Taipei, which was reflected to the rear-view mirror, travelling to an old town in southern Taiwan. These two images imply the competing tendency of concerning historical heritage in Taiwan today while globalisation and urbanisation are leading the world as the mainstream trend (Cape No.7, directed by Wei Te-Sheng, Taiwan, 2008. Buena Vista).

With the transition of geographic identification, representations of nostalgia in the built environment illustrate more explicit characteristics of the making of Taiwan's post-war idealised spaces. Two typical sets of nostalgic space signify post-war architectural ideologies in Taiwan - Washitsu and the Minnan style house. First, Washitsu (Figure 12) can be regarded as the most distinctive idealised space in post-war Taiwan. Practically, the Japanese style room is always a common room setting in the houses of most Taiwanese families since the Japanese time. This room, interestingly, seems to be idealised as a vital spatial icon with meaning across cultures, ethnicities, ages and functions in the post-war built environment in Taiwan (Figure 13). In A City of Sadness, Washitsu is a room providing social activities, communication, negotiation and active living space, and even hospital wards in early post-war Taiwan. In A Brighter Summer Day, Washitsu not only can be a temporal place for most of the Mainlanders but also can be the luxury villa for a privileged mainland Chinese general. In very recent films, Washitsu frequently appears as an interior archetype in modern Taiwanese buildings no matter their type, function or cultural base. Although the form of Washitsu in Taiwan originated from Japan, this room today has been idealised and indigenised as an icon indicating typical modern Taiwanese living space. To be precise, the use of Washitsu today in Taiwan society, as an element of post-war Taiwan's spatial hybridisation, has constructed a unique form of identity transcending its origination and symbolic meaning. No matter whether Washitsu is from Japan originally or not, no matter whether the new generation of the Taiwanese know that it is from Japan originally or not, Washitsu has been widely recognised as a vitally important icon of Taiwanese living space today. Of course, this space is idealised for identification psychologically. As far as the exact function of Washitsu in Taiwan today, which would legitimise the essential of its existence, interestingly, it is no doubt less important or even unmeaning for most of the Taiwanese people in this day and age.

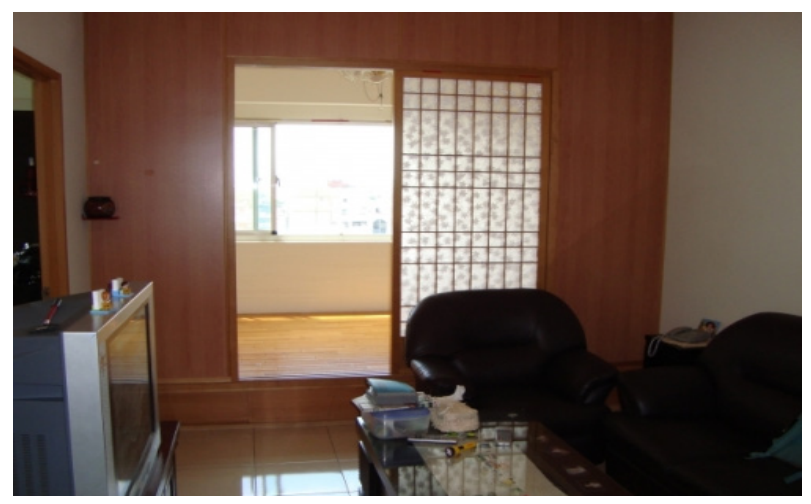

Figure 12. The typical setting of Washitsu in post-war Taiwanese architecture (Taken by the author).

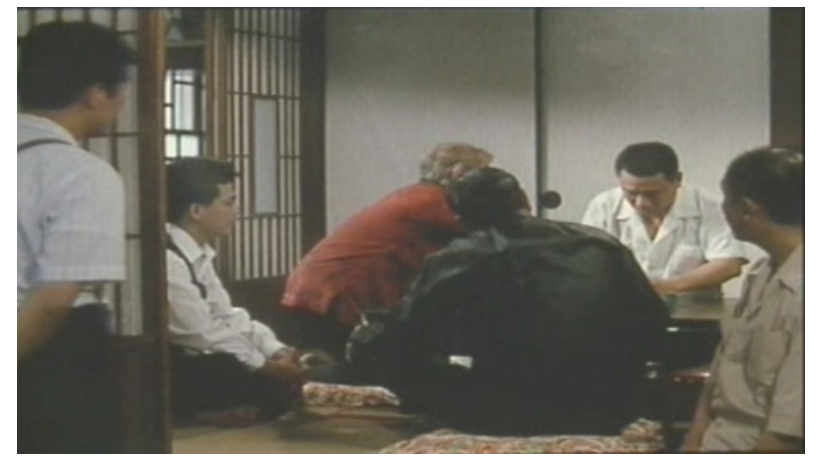




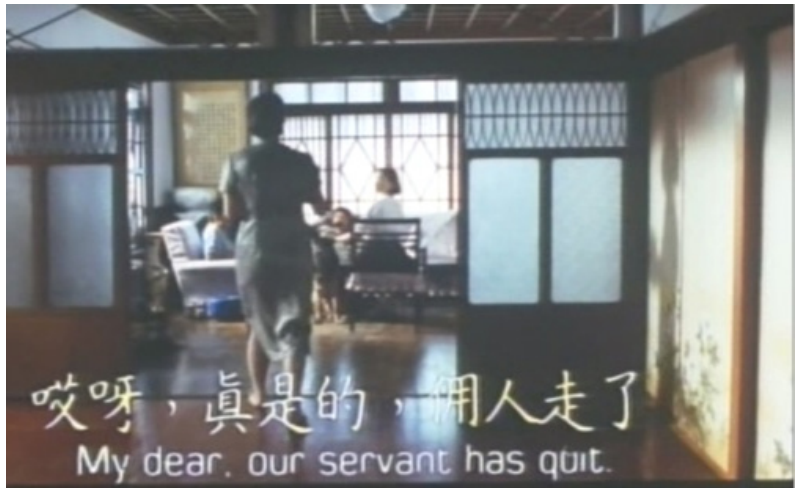

Figure 13. Images of Washitsu filmed in cinematic works to represent different functions, social status and symbolic meanings (Up: A City of Sadness, 1989. Down: A Brighter Summer Day, 1991).

Unlike Washitsu's multi-definitions in post-war Taiwan space, the Minnan style house (Figure 14) is strictly associated with islander-ethnicities, albeit ironically that this space has its origins in China. Seen in film, to a certain degree, the Minnan house provides an established atmosphere as a nostalgic "home" for native ethnic groups. As an idealised Taiwanese house, three elements always stand out, namely: (1) certain sections with compounds (usually one depending on the financial affordability of the family), (2) a central courtyard amongst all the compounds (or simply just a semi-open front field), and (3) a strong symmetrical axis which indicates different positions in the family hierarchy. These elements, therefore, constitute a stable sense of belonging. For instance, from Blue Brave: the Legend of Formosa in 1895 (which reconstructs the time of 1895), A City of Sadness (which reconstructs the time of very early post-war Taiwan in urban area), Duo Sang: A Borrowed Life (which reconstructs the time of very early post-war Taiwan in rural area), The Boys from Fengkoei (which captures real space in 1983), Dust of Angels (depicting real space in1992), Island Etude (depicting real space in 2007) to Cape No.7 (depicting real space in 2008), the Minnan house occupies the nostalgic position as an idealised "home" for native families, no matter whether from the Japanese era or from the most recent times. Next, the courtyard of the Minnan house and the central lobby of the building pinpoint the core of family activities like communication and important ceremonies. Like Washitsu in Taiwan, the Minnan house is evident today in Taiwan society as an idealised space, especially from the transfiguration of the central lobby. It is a fact that even though the Minnan house is no longer used as the majority of modern Taiwan's residential building types, the centre of the floor plan in most native apartments can still be implied as the space of the core and pivotal ceremony in a family at the present time (Figure 15). In comparison to the strong atmosphere which the native ethnic groups have created in the Minnan style house, A Brighter Summer Day which describes the early post-war lives of Mainlanders in Taiwan, presents in stark contrast an uncertain, forceless and placeless ambience for the Mainlanders' family. More precisely, without the idealised or organised space, the Mainlanders' sense of belonging to this island becomes even weaker when they take the privilege to occupy the properties the Japanese left behind or to create an imaginary "China" by establishing the so-called "military village" in post-war Taiwan.

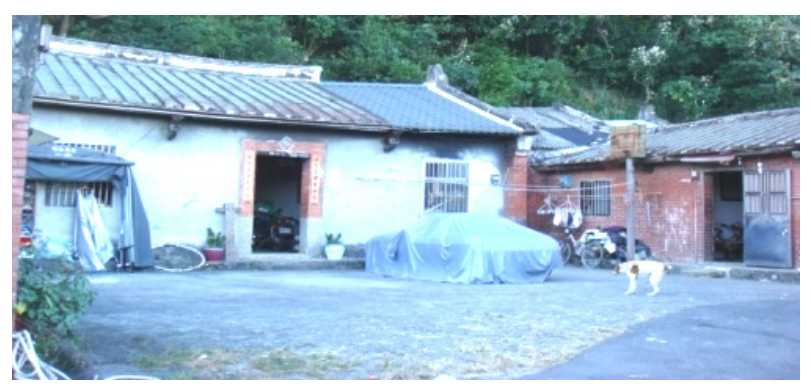

Figure 14. The image and atmosphere of the main section of the Minnan style house in Taiwan. The middle building usually functions ceremonial activities for ancestors and gods as the most important space in the family hierarchy (Taken by the author).

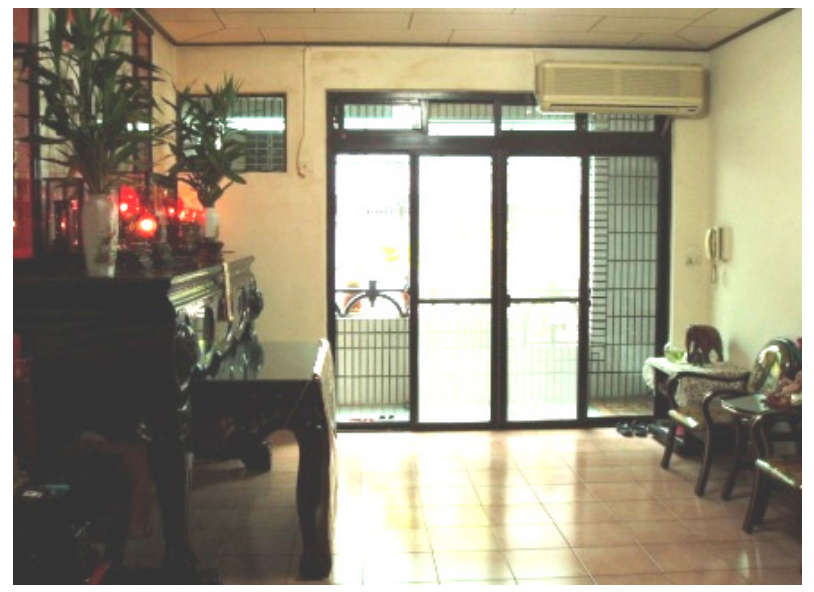

Figure 15. The typical core family place in modern Taiwanese apartment (usually is combined with the living room through placing a desk for family activities or memorial ceremony for the ancestors) implies the idealised central lobby of the Minnan House (Taken by the author).

\section{Conclusion: a form of appropriate fuzziness in post-Martial Law Taiwan's built environment}

To be concluded, by examining different cultural forms in post-Martial Law Taiwan, particularly their (re)representations of the built environment, it denotes an uncertainty which translates Taiwan society's anxiety about transiting quotidian lives from a once repressed atmosphere to an open once. This anxiety is driven by the presence of the authoritarian residues which have not disappeared because of Taiwan's democratisation today. However, in the built world, a fuzzy form is generated, through different ways such as redefining urban-countryside distance, transiting geographic identification, and idealising external and nostalgic spaces, to proper mediate this anxiety 
between the yet passed dictatorship and the seemingly democratic present in Taiwan society that translated in its physical space. A heteroglossic context, as a form of this appropriate fuzziness, intertextualises different architectural objects as a whole.

The cultural and spatial context on the island today is neither purely colonial nor insular (anti-colonial) but relatively neutral and cosmopolitan. The situation is like what Taylor says: "the relics cannot stand alone in time or space; they should have relevance for the community around them rather than simply relevance for "the nation", [6]. A proper statement of the cultural political identification of the island today in Taiwan as a broader conclusion of examining the built environment perhaps is similar to J Bruce Jacobs's description that: "A concise statement sometimes heard in Taiwan today, people no longer say, "Taiwan culture is a part of Chinese culture". Rather, they say, "Chinese culture is a part of Taiwan culture along with aboriginal cultures, Dutch culture, Spanish culture, Manchu culture, Japanese culture and Western culture" [7].

\section{REFERENCES}

[1] T. H. Chu. The Old Capital: a novel of Taipei, Modern Chinese literature from Taiwan. New York: Columbia University Press, 111, 2007.

[2] F. Jameson. The geopolitical aesthetic: cinema and space in the world system. Bloomington; London: Indiana University Press, 154, 1992.

[3] P. Bourdieu. "The biographical illusion." In Identity: a reader, edited by Paul Du Gay, Jessica Evans, Peter Redman and Open University, 297-303. London; Thousand Oaks, Calif.: SAGE Publications in association with The Open University, 302, 2000.

[4] R. Williams. Keywords: a vocabulary of culture and society. Flamingo ed. London: Fontana Paperbacks, 1983.

[5] T. M. Lee. "A hundred years of Taiwan cinema." Historical Monthly, Vol. 158, 42-43, 2001.

[6] J. E. Taylor. "Reading History Through the Built Environment in Taiwan." In Cultural, ethnic, and political nationalism in contemporary Taiwan: bentuhua, edited by John Makeham and A. chin Hsiau, 159-183. New York: Palgrave Macmillan, 171, 2005.

[7] J. B. Jacobs. "Taiwan Studies in Australia." Issues \& Studies Vol.43, No.1, 218, 2007. 